JGG 2022;70:83-85

doi: 10.36150/2499-6564-N324

\title{
Radiographic pulmonary description of bilateral multifocal patchy with ground- glass opacifications needs careful evaluation in the Era of SARS-CoV-2
}

Sara Gabriele, Sergio Minervini, Roberto Schepisi, Mariana Peroni, Marlene Dall'Alda, Daniela Broch, Domenico Recchi, Daniele Longo, Marco Camin, Renzo Girardello

Department of Medicine, Section Geriatrics, Rovereto Hospital, Azienda Provinciale per i Servizi Sanitari (APSS), Trento, Italy

In the COVID-19 Era, multilobe ground-glass opacities (GGOs) and septal thickening on chest Computed Tomography (CT) have been recognized as a radiological finding highly suggestive for SARS-CoV-2 pneumonia. However, these findings can be misleading. Here, we report about an 81-year-old woman, evaluated in the Emergency Room (ER) for a traumatic hip fracture, who, despite negative molecular testing on the nasopharyngeal sample for SARS-CoV-2, was admitted to a COVID-Unit because of flu-like symptoms with GGOs and interlobular septal thickening on the chest CT. During the hospital stay, focusing on the patient's medical history, the interstitial lung disease was defined to be a chronic complication of long-term use of Amiodarone and rheumatoid arthritis. Therefore, especially during SARS global pandemic, CT pathological findings suggestive for interstitial pneumopathy should be critically analyzed considering patient history. They can reflect, in fact, other pathological conditions different from SARS-CoV-2 infection as other viral and non-viral infections or chronic inflammatory diseases.

Key words: SARS-CoV-2 infection, chest Computed Tomography, interstitial pneumonia, ground-glass opacities

\section{INTRODUCTION}

nervini S, Schepisi R, et al. Radiographic pulmonary description of bilateral multifocal patchy with ground-glass opacifications needs careful evaluation in the Era of SARS-CoV-2. Journal of Gerontology and Geriatrics 2022;70:83-85. https://doi. org/10.36150/2499-6564-N324

(C) Copyright by Società Italiana

di Gerontologia e Geriatria (SIGG)

(c) (1) () $(9$

OPEN ACCESS

This is an open access article distributed in accordance with the CC-BY-NC-ND (Creative Commons Attribution-NonCommercial-NoDerivatives 4.0 International) license. The article can be used by giving appropriate credit and mentioning the license, but only for non-commercial purposes and only in the original version. For further information: https://creativecommons.org/licenses/by-nc-nd/4.0/deed.en

The diagnosis of infection of severe acute respiratory syndrome coronavirus 2 (SARS-CoV-2) is possible after detection of its RNA on nasopharyngeal swab samples by nucleic acid amplification tests (NAATs). In some cases, however, there may be false-negative results depending on swab type, operator, and time since symptoms onset ${ }^{1,2}$. In a setting of strong clinical suspicion with negative initial NAAT, a combination of laboratory, chest Computed Tomography (CT) images and the repetition of the molecular test may be beneficial for the diagnosis ${ }^{3,4}$.

Patients with SARS-CoV-2 pneumonia normally present fever, dyspnea, cough, and marked fatigue. They usually show on laboratory test lymphopenia, elevated aminotransaminase, lactate dehydrogenase, ferritin, Creactive protein, D-dimer, and erythrocyte sedimentation rate levels ${ }^{5}$. Their initial chest radiographs can be initially normal but progressively show multifocal peripheral airspace consolidations. Chest CT main findings are 
ground-glass opacities (GGOs) while multifocal consolidations, septal thickening, development of a crazypaving pattern are gradually observed over time ${ }^{6,7}$.

\section{CASE PRESENTATION}

During the first period of the SARS-CoV-2 pandemic, an 81-year-old woman was admitted to the Emergency Room (ER) for hip pain after suffering a fall. She had not any close contact with anyone infected by SARSCoV-2, but she lived in a small village with a significant diffusion of the viral infection.

The woman showed no symptoms of upper and lower respiratory tract infection but flu-like symptoms with diarrhea and fatigue. No smell or taste disturbances were reported either. She was suffering from arterial hypertension, ischemic heart disease, mitral valve replacement with a mechanical prosthesis, pacemaker implant for the tachybrady syndrome, seronegative rheumatoid arthritis (2010), lymphocytic colitis (2012), and pulmonary fibrosis (2017). No reference was made to tobacco habits. The patient had been under extended treatment with Hydroxychloroquine, Budesonide, Amiodarone, Metoprolol, Vitamin K Antagonist, Loop Diuretics, Proton Pump Inhibitor. Both rapid antigens testing and NAAT on nasopharyngeal samples resulted in negative. On the blood chemistry tests nothing to report except for mild leukopenia $\left(2.5 \times 10^{\wedge} \mathrm{g} / \mathrm{L}\right)$ and a slight increase in C-reactive Protein (5.2 mg/L), LDH (266 U/L), and D-dimer (589 ng/ml). Chest CT scan showed bilateral multifocal patchy with GGOs in both lower lobes (Fig. 1). The patient was admitted to the COVID-Unit with a diagnosis of SARS-CoV-2 pneumonia based on atypical symptoms, laboratory alteration, and especially radiographic evidence. After 48 hours, the second NAAT excluded viral infection, too. A few days later the patient was discharged from the hospital with the final diagnosis of accidental hip trauma, reactivation of chronic colitis, and pulmonary fibrosis (as previously diagnosed).

\section{DISCUSSION}

In our case, although the pre-test probability of infection was low (atypical symptoms and generic community risk infection) and the microbiological test was negative, the diagnosis of SARS-CoV-2 disease was wrongly made through common abnormal laboratory and especially radiographic features analysis. However, the interstitial lung disease was already present in the patient's clinical history, and it was probably due to rheumatic disease and chronic use of Amiodarone. Pulmonary fibrosis represents a heterogeneous group of disorders due to a broad range of diseases, exposures,

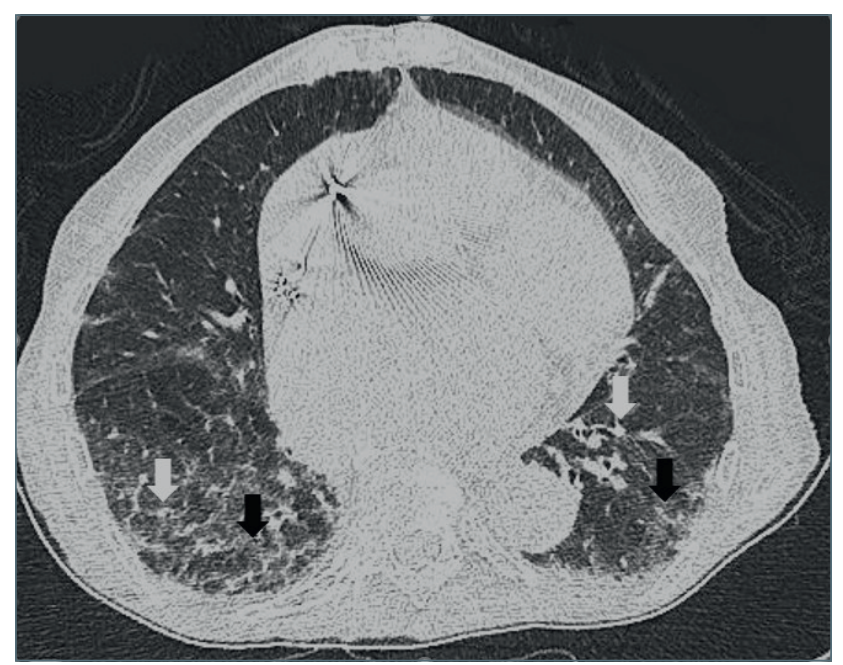

Figure 1. Chest Computed Tomography scan showing interstitial thickening (white ar-rows) and ground-glass opacities (black arrows) involving multiple lobes in both lungs.

viral respiratory infections, and drugs ${ }^{8,9}$. The radiologic features of SARS-CoV-2 are similar to those of other community-acquired types of pneumonia, such as Influenza $A(H 1 N 1), C M V$, others coronavirus (SARS, MERS), streptococcal, and pneumonia atypical germs (Chlamydia, Mycoplasma). Nevertheless, some CT features of viral pneumonia are variable and may be affected by the immune status of the host and the pathogenic processes induced by the specific virus ${ }^{10}$.

This clinical case shows some common difficulties in the management of patients with suspect of SARS-CoV-2 infection but negative initial NAAT. The SARS-CoV-2 Era has required an urgent revolution in the healthcare system regarding the management and control of the infection, and clinicians can be sometimes faced with doubtful cases of infection and the necessity to decide quickly whether to consider them infected or not ${ }^{11,12}$. Over this period, the main effort has been to keep infected people separated from the others to avoid viral diffusion. So far, hospitalized patients suspected of having SARS-CoV-2 infection but with negative NAAT were usually admitted to COVID-Unit, as the priority was to keep "clean" the non-SARS-CoV-2 wards. Following this principle, our patient was hospitalized for 10 days in a COVID-Unit. Despite this high risk of contagion, the patient never presented the viral infection.

\section{CONCLUSIONS}

Even if highly suggestive, imaging features alone are not enough for the diagnosis of SARS-CoV-2. The CT findings need to be correlated with symptoms, medical 
history, physical exams, laboratory, and microbiological tests. Therefore, especially during the worldwide outbreak, the interstitial parenchymal lung disease showing multifocal patchy with GGOs should be interpreted with caution and shed light on through differential diagnosis, comparing it with other clinical situations.

\section{Ethical consideration}

None.

\section{Acknowledgement}

Everyone who contributed significantly to the work appears in the list of authors.

\section{Funding}

This research did not receive any specific grant from funding agencies in the public, commercial, or not-forprofit sectors.

\section{Conflict of interest}

The authors declare to have no conflict of interest.

\section{References}

1 Long DR, Gombar S, Hogan CA, et al. Occurrence and timing of subsequent severe acute respiratory syndrome coronavirus 2 reverse-transcription polymerase chain reaction positivity among initially negative patients. Clin Infect Dis 2020;XX:1-4. https://doi.org/10.1093/cid/ciaa722

2 Weissleder R, Lee H, Ko J, Pittet MJ. COVID-19 diagnostics in context. Sci Transl Med 2020;12:1-7. https://doi. org/10.1126/scitranslmed.abc1931

3 Shi $\mathrm{H}$, Han $\mathrm{X}$, Jiang $\mathrm{N}$, et al. Radiological findings from 81 patients with COVID-19 pneumonia in Wuhan, China: a descriptive study. Lancet Infect Dis 2020;20:425-434. https://doi.org/10.1016/S1473-3099(20)30086-4
4 Abedi SA, Balakrishnan S, Gholamrezanezhad A. Coronavirus disease 2019 (COVID-19): a systematic review of imaging findings in 919 patients. AJR Am J Roentgenol 2020;215:1-7. https://doi.org/10.2214/AJR.20.23034

5 Wang $\mathrm{D}, \mathrm{Bo} \mathrm{H}, \mathrm{Hu} \mathrm{C}$, et al. Clinical characteristics of 138 hospitalized patients with 2019 novel coronavirusinfected pneumonia in Wuhan, China. JAMA - J Am Med Assoc 2020;323:1061-1069. https://doi.org/10.1001/ jama.2020.1585

6 Vancheri SG, Savietto G, Ballati F. et al. Radiographic findings in 240 patients with COVID-19 pneumonia: time-dependence after the onset of symptoms. Eur Radiol 2020;30:6161-6169. https://doi.org/10.1007/ s00330-020-06967-7

7 M Chung, Bernheim A, Mei X, et al. CT imaging features of 2019 novel coronavirus (2019-NCoV). Radiology 2020;295:202-207. https://doi.org/10.1148/ radiol.2020200230

8 Travis WD, Costabel U, Hansell DM, et al. An official American Thoracic Society/European Respiratory Society statement: update of the international multidisciplinary classification of the idiopathic interstitial pneumonias. Am J Respir Crit Care Med 2013;188:733-748. https://doi. org/10.1164/rccm.201308-1483ST

9 Jin $\mathrm{YH}$, Cai L, Cheng Z-S, et al. A rapid advice guideline for the diagnosis and treatment of 2019 novel coronavirus (2019-nCoV) infected pneumonia (standard version). Mil Med Res 2020;7:1-23. https://doi.org/10.11855/j. issn.0577-7402.2020.01.01

$10 \mathrm{Koo} \mathrm{HJ}$, Lim S, Choe J, et al. Radiographic and CT Features of. RadioGraphics 2018;38:719-739.

11 Emanuel EJ, Persad G, Upshur R, et al. Fair allocation of scarce medical resources in the time of COVID-19. N Engl J Med 2020;382:2049-2055. https://doi.org/10.1056/ NEJMsb2005114

12 Chu DK, Akl EA, Duda S, et al. Physical distancing, face masks, and eye protection to prevent person-to-person transmission of SARS-CoV-2 and COVID-19: a systematic review and meta-analysis. Lancet 2020;395:1973-1987. https://doi.org/10.1016/S0140-6736(20)31142-9 